\title{
Iconografía y estética de Mad Men: un análisis de su discurso visual desde el las corrientes pictóricas norteamericanas
}

\author{
María de Lourdes López Gutiérrez ${ }^{1}$ \\ Universidad Panamericana, Ciudad de México
}

\section{RESUMEN}

Mad Men presenta la transición de la vida industrial a la bonanza del consumo: imágenes y objetos son portavoces de un mundo edulcorado por los medios, desplazando el gusto clásico hacia los valores estéticos norteamericanos de la cultura popular y las corrientes artísticas de la posguerra en Estados Unidos. Los recursos escénicos y audiovisuales de la serie responden a los principios de las escuelas americanas de pintura de esa época.

El objetivo de este trabajo es analizar la composición icónica de la serie a la luz de la estética realista de Edward Hooper, la ilustración de los años 50 y el expresionismo abstracto como principios visuales que aportan al potencial semántico del discurso, así como los valores estéticos de la contracultura que atravesaron los espacios del establishment americano representado en la serie.

Palabras clave: Mad Men, iconografía, realismo, expresionismo abstracto, arte pop

\section{ABSTRACT}

Mad Men presents the transition from industrial life to the wellness of consumption: images and objects represented a world sweetened by the media, shifting the classic taste to American aesthetic values. The scenic and audiovisual resources of the series respond to the principles of American painting schools.

The purpose of this work is to analyze the iconic composition of the series based on the realistic aesthetics of Edward Hooper, the illustration of the 1950s and abstract expressionism as visual principles that contribute to the semantic potential of discourse as well as aesthetic values of the counterculture that crossed the spaces of the american establishment represented in Mad Men.

\footnotetext{
${ }^{1}$ Comunicóloga, Maestra en Ciencias de la Educación, candidata a Doctora en Historia del Pensamiento. Es profesora investigadora de la Escuela de Comunicación en la Universidad Panamericana. Correo electrónico:

mllopezg@up.edu.mx
} 
Keywords: Mad Men, iconography, realism, abstract expressionism, pop art 


\section{INTRODUCCIÓN}

¿Qué hace que las series de hoy sean tan atractivas, tan diferentes?

Ésta es la pregunta que podría hacerse Richard Hamilton si hoy iniciara una exposición a propósito de los gustos por el consumo de la cultura popular.

En aquella exposición en Londres, en 1956, This is Tomorrow el collage emblemático que marca el inicio del arte pop nos muestra a una pareja atrapada en el culto al cuerpo, en un departamento en el que la televisión, el aparato reproductor de música, la comida enlatada y un enorme viñeta de historieta enmarcan la escena de la vida cotidiana, con una sala de cine tan cercana que parece parte del pequeño apartamento. En segundo plano hay una mujer con una moderna aspiradora y al fondo el logotipo de Ford, casi como un trofeo. El título de la obra: “¿Qué es lo que hace que las casas de hoy sean tan atractivas, tan diferentes?"

La intención de Hamilton era aludir a aquellos objetos que definen la atmósfera de la sociedad de consumo como válvula de escape para el ambiente de la posguerra. El optimismo con el que los productos culturales mediatizados fueron adoptados e insertados en la vida cotidiana, explica el glamur que ro- dea al mundo de los medios, la moda y el estatus definido por el poder adquisitivo. La presencia de imágenes y objetos como portadores de bienestar y como voceros de un mundo edulcorado por la televisión, el cine, la publicidad e incluso el arte, significó el desplazamiento del gusto hacia lo banal, hacia aquello que suponía dejar atrás las difíciles décadas de la depresión y las guerras mundiales.

El paradigma europeo cedía lugar al norteamericano que prometía un mundo más asequible y democrático al poner al alcance de más gente aquello que proveía estatus, imagen y éxito social. La cantidad de clichés fabricados a partir de la idea de desarrollo, bienestar y oportunidades para todos, fueron permeando el lenguaje de los medios hasta instalarse como un corpus ideológico del mundo moderno.

Mad Men es una serie representativa de esos años: los años del advenimiento de la sociedad de consumo y la transición de la década del 60, focalizada desde el establishment y desde la maquinaria que legitimaba el discurso mediático como catalizador de los deseos más profundos de la gente: el mundo de la publicidad. En las décadas de la posguerra, Estados Unidos no solo se convirtió en el paraíso del consumo de masas sino en el rector de las modas y tendencias culturales de la época. 
Aquí una breve sinopsis: la serie narra la vida de Don Draper, director creativo de la agencia Sterling \& Cooper, quien por un lado logra posicionar a la agencia en el competido mundo de la publicidad y por otro enfrenta el íntimo drama de una infancia difícil, el cambio de identidad, la imposibilidad de mantener una relación sin infidelidades e incluso su adicción al alcohol.

A lo largo de siete temporadas somos testigos de las modificaciones de la agencia no solo en su crecimiento como empresa sino su adaptación a un mundo que experimentó en poco tiempo el cambio de las más rancias estructuras sociales. Draper es exitoso profesionalmente pero, va destruyendo paulatinamente sus relaciones interpersonales y familiares.

El objetivo de este trabajo es analizar cómo la puesta en escena y los recursos cinematográficos de la serie son un documento que recoge los valores estéticos de las escuelas pictóricas norteamericanas, del realismo iniciado por la Escuela de Ashcan hasta la estética colorida, apolítica y ornamental del op-art y las múltiples herencias del expresionismo abstracto y el pop. De ahí que en este trabajo se busque la articulación de la propuesta iconográfica de la serie con los acontecimientos narrados que van contextualizando la aparición de las nuevas tendencias plásticas y su asimilación en los espacios en los que transcure la historia.

La metodología utilizada para el análisis aborda primeramente la identificación de la construcción iconográfica tanto de las obras artísticas referenciadas como de la propia serie, con énfasis en los elementos constitutivos de la imagen: forma, líneas, color, composición, textura para posteriormente interpretar su contenido simbólico a la luz del contexto histórico en el que son producidas ambas propuestas visuales.

Por otro lado, se realizó un visionado de la serie enfocado a las obras de arte que aparecen en ella considerándolas como unidades indiciales, lo que las integra al discurso como elementos de significación.

\section{EL ESPACIO FÍLMICO: ICONICIDAD Y ESTÉTICA}

El espacio fílmico es un elemento narrativo que no solo sirve como escenario de la acción sino que es en sí mismo un recurso de transmisión de significados (Gaudreault y Jost, 1995). Puede ser abordado en primera instancia a partir de los elementos primarios de composición de la imagen: el plano, la angulación, los movimientos de cámara, etc.

La imagen en el discurso audiovisual cumple dos funciones: la iconicidad, que es la 


\section{-}

capacidad comunicativa de los elementos que aparecen en pantalla y que está directamente relacionada con la competencia cultural del espectador para comprender el significado de los elementos que ve (Casseti y Di Chio, 1995) y la función estética, definida fundamentalmente por los recursos fotográficos que permiten la manipulación de las texturas, colores, saturación, etc., así como la infinita gama de ambientes que brinda la iluminación.

El espectador reconoce no solo los objetos y los sujetos que se muestran en el cuadro, sino que hace una lectura más profunda, inconsciente a veces, sobre cómo aparecen, es decir, identifica el valor expresivo del plano y la intención comunicativa del encuadre. Además, a través del montaje, el espectador arma el espacio total de la acción, aun cuando éste no se muestre nunca en planos abiertos. Los espacios son elocuentes al envolver al personaje en un ambiente polisémico: todo aquello que ve el espectador será integrado a la comprensión de la historia y a su valoración estética.

"El papel del espectador, según Gombrich, es un papel extremadamente activo: construcción visual del reconocimiento, activación de los esquemas de la "rememoración" y ensamblaje de uno a otra con vistas a la construcción de una visión coherente del con-
María de Lourdes López Gutiérrez

junto de la imagen" (Gombrich, citado por Aumont, 1992, p. 95). Este enunciado otorga al espectador un papel activo y nos remite al principio de que todos tenemos "modos de ver", es decir, la lectura de una imagen está marcada por la subjetividad de quien mira.

$\mathrm{Si}$ es el espectador quien dota de sentido a la imagen, los indicios que hay en ella serán su materia prima de lectura, por ello es necesario aludir también a las unidades de significación propuestas por la narratología y la teoría estructural del relato (Barthes, 2004).

Las unidades funcionales son aquellos elementos, escenas, acciones (diálogos, miradas, acontecimientos) que abonan al desarrollo de la historia; las unidades indiciales, o indicios, son los recursos icónicos, sonoros, lingüísticos o actanciales que dan información al espectador para identificar el lugar, la época, la cultura de la historia y además permiten reconocer los generales de los personajes ( $\mathrm{ra}-$ za, condición sociocultural, clase social, personalidad, etc.).

Los indicios iconográficos que más nos interesan son las pinturas que aparecen en la serie, las cuales adquieren significado en función del resto de los elementos: "Cuando la pintura entra al espacio cinematográfico se vuelve parte del discurso audiovisual. ...esta se convierte inevitablemente en material para 
el argumento del realizador" (Berger, 2005, p. 33).

La referencia temporal de Mad Men a lo largo de sus siete temporadas va de 1959 a 1971. En ocasiones hay referencias claras en los diálogos..."Bien, señores, empecemos con 1965", dice Joan al final del tercer episodio en la cuarta temporada; pero son los hechos históricos o culturales los que van dando la pauta temporal, como la derrota electoral de Nixon, el asesinato de John F. Kennedy y de Martin Luther King o la llegada del hombre a la luna, pero también los programas de televisión, el triunfo inglés en el mundial de futbol, la música (un resignado Draper que lleva a su hija Sally a un concierto de Los Beatles, por ejemplo) y los cambios en la moda, el mobiliario y los objetos en las casas y oficinas (desde el sofá Dunbar que compra Betty Drapper en la tercera temporada hasta la computadora que tanto escepticismo causa en los miembros menos jóvenes de la agencia).

En este itinerario, los espacios cinematográficos tienen su propia personalidad; empecemos con aquellos espacios que de manera más clara remiten a una de las grandes premisas de la serie: la soledad de los personajes en medio de la atractiva y dinámica vida en Manhattan.

\section{EL REALISMO EN LA PINTURA: LA DECEPCIÓN DEL SUEÑO AMERI- CANO Y LA DEUDA DE MAD MEN CON EDWARD HOOPER}

El término "sueño americano"! fue acuñado por el historiador James Truslow Adams en 1931, en The epic of America, en donde lo define como “...el sueño de una tierra donde la vida debería ser mejor y más rica para cada hombre, con oportunidades para cada habilidad y oportunidad" (Adams, 2012).

En el sueño americano caben no solo los ideales de libertad y bienestar; en él se inscriben las banderas enarboladas por ese país desde el siglo XIX: la democracia, el desarrollo económico y un estilo de vida donde los bienes de consumo se relacionan directamente con la idea de felicidad y plenitud. Esta última construcción del sueño americano debe mucho a la cultura popular.

A propósito de Mad Men: "Don es para sus contemporáneos una leyenda americana, el nuevo hombre de la frontera, el exultante creador de lo que Gilbert Durand denominó la Sinfonía heroica del Progreso. Pertenece a la estirpe de esos triunfadores de la sociedad opulenta que ya no trabajan por la mera supervivencia ni para evitar la inseguridad económica, sino en pos de una elevada gratifica- 
ción económica que se corresponde con una nueva forma de prestigio" (Ros, 2016, p. 71).

Sin embargo, la pintura norteamericana de finales del siglo XIX recupera el mensaje social de las corrientes realistas europeas, proporcionando una mirada diferente del paisaje urbano, una contrapropuesta a las imágenes de los grandes rascacielos que empezaban a erigirse como símbolos de progreso tecnológico e industrial. La otra cara de la moneda fue la mostración pictórica y fotográfica de la pobreza (Bernárdez, 2012).

Bajo la consigna de "pinta la vida como es", el grupo bautizado como Ashcan se formó con artistas algunos de los cuales venían de trabajar como ilustradores en periódicos o del fotoperiodismo, lo que explica su visión directa de la vida americana. Con una técnica pictórica heredera del post impresionismo, los pintores de la escuela de Ashcan revelaron el carácter solitario y casi poético de las noches neoyorkinas como un halo envolvente de las escenas de la gente común (Soufer, 2015).

Edward Hooper abrevó de ellos la intención de recuperar esas atmósferas. Hooper es el gran representante del realismo norteamericano de las décadas posteriores a la depresión y el principal referente pictórico de la composición de aquellas escenas de Mad Men que buscan reflejar el carácter solitario o bucólico de los personajes.

No es cuestión menor el hecho de que la acción de la serie se ubique en una de las zonas más prestigiadas de Nueva york, la calle Madison (en donde están las agencias publicitarias y que precisamente daría origen al término mad men) y que sin embargo su fotografía evoque irremediablemente la tradición realista de Ashcan y sobre todo de Hooper. El entorno es la riqueza, la imagen remite a la soledad: una suerte de contra discurso que constituye un mecanismo narrativo paradójico, que suma a la complejidad de los personajes.

La serie se desarrolla en varios planos argumentales, si bien la linealidad cronológica es un recurso que permite el entramado de la acción que avanza fielmente con el calendario de la década, la gran apuesta narrativa está en el desarrollo de personajes complejos, de emocionalidad contenida (Martín, 2013), que se mueven en el mundo frívolo y próspero de Manhattan pero que en ocasiones parecen ser sorprendidos por la cámara en una íntima y profunda soledad, recuperada en cuadros que evocan el estilo realista, urbano y melancólico de Hooper.

A diferencia de sus maestros de Ashcan, Hooper se inclina por la composición arqui- 
tectónica del cuadro, lo cual hace más sentido con el entorno urbano en el que las formas orgánicas son escasas para dar paso a la geometría de paredes, ventanas, muebles o barras de un bar. El uso de colores sólidos oscuros y de la sugerencia de una luz artificial, realista y poco poética que ilumina tristemente las escenas son cualidades representativas que hacen de la pintura de Hooper la descripción de la soledad humana en una de las ciudades que empezaban a registrar más movimiento y crecimiento urbano (Wells, 2012).

Los personajes están supeditados al espacio, que los envuelve y los encierra en su propio pensamiento. Las escenas sugieren silencio aun cuando se trate de lugares públicos como cafeterías, restaurantes, hoteles, cines u oficinas. La pincelada de Hooper no entra al detalle de los rostros o los objetos, los esboza al estilo de la pintura moderna con la suficiente elocuencia como para adivinar su ensimismamiento. Los espacios, a pesar de la gran ciudad, están siempre semivacíos.

La pintura de Hooper ha sido un paradigma para la cinematografía estadounidense; los tiros de cámara remiten con frecuencia a sus composiciones, su paleta de colores y el uso de la luz.

La construcción geométrica, la ubicación de la persona humana supeditada al entorno, la luminosidad escasa y el énfasis en las situaciones cotidianas en lugares comunes son los elementos de Mad Men que remiten a Hooper (cuadros 1 y 2).

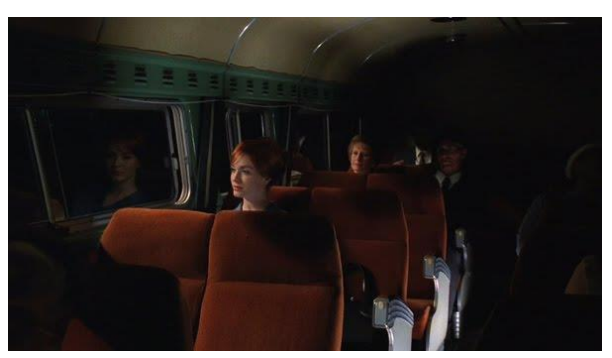

Cuadro 1. Mad Men. T2E6

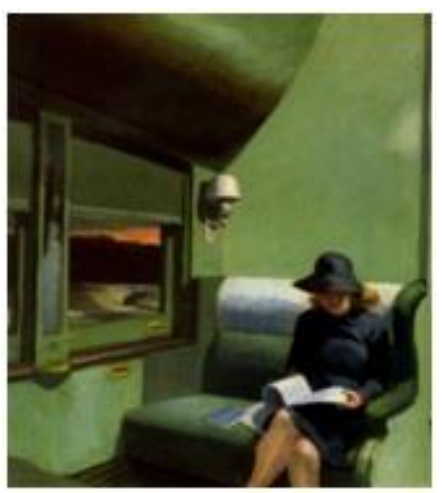

Cuadro 2. Edward Hopper. Compartimento C

\section{LA ILUSTRACIÓN COMO REFLEJO DEL IDEAL FAMILIAR}

Por otro lado, encontramos en la serie algunas escenas de la familia norteamericana más conservadora y con menos poder adquisitivo cuya estética comparte cualidades de la ilustración clásica de Harold Anderson o Norman Rockwell, los ilustradores que construyeron un discurso icónico de la vida ideal del norteame- 
ricano medio muy popular en revistas y anuncios publicitarios.

Con la herencia del modernismo francés, que confirió a la ilustración un status artístico, los ilustradores norteamericanos imprimieron valor estético propio a la representación de las escenas que recogían los momentos emblemáticos de la vida cotidiana para convertirlos en íconos de la cultura, en referentes visuales a un mundo compartido por la gente común pero que se representaba como el entorno adecuado para el progreso económico y el desarrollo personal (Reed, 2001).

Las escenas familiares no abundan en Mad Men. Cuando las hay, están invariablemente asociadas a desencuentros, conflictos o momentos de alta tensión; sin embargo, su construcción icónica remite a las imágenes fraguadas por la publicidad y la ilustración mencionadas, en revistas que promovían a la familia como elemento aglutinante de la sociedad del bienestar. Nuevamente la composición como contra discurso. En estas imágenes prevalece la forma orgánica, generalmente los personajes aparecen dispuestos alrededor de un objeto que se convierte en el motivosímbolo principal, en colores cálidos y realizando alguna acción (al contrario de la inmovilidad introspectiva de los cuadros hooperianos).
Las revistas ilustradas fueron, durante décadas, la forma principal de entretenimiento masivo. Anderson fue ilustrador de Liberty Magazine, una revista de corte religioso, fundada en 1924, y que semanalmente influyó en los estados de ánimo, estilos de vida y formas de asimilar los acontecimientos, como las dos Guerras Mundiales, de millones de ciudadanos norteamericanos hasta 1950, año en que dejó de ser editada.

En los cuadros 3 y 4 mostramos algunos ejemplos de la relación de la serie con la ilustración:

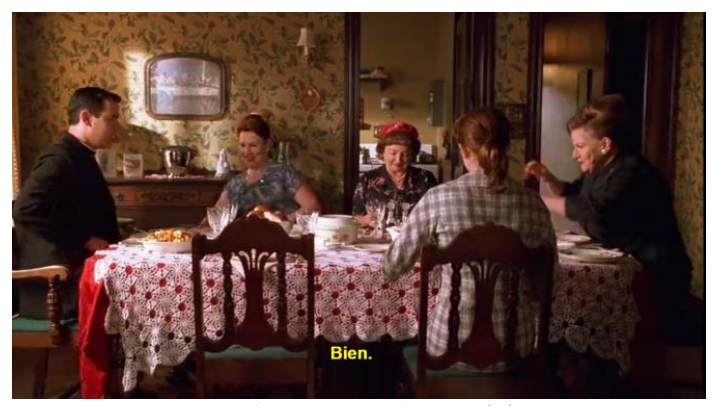

Cuadro 3. Mad Men. T1

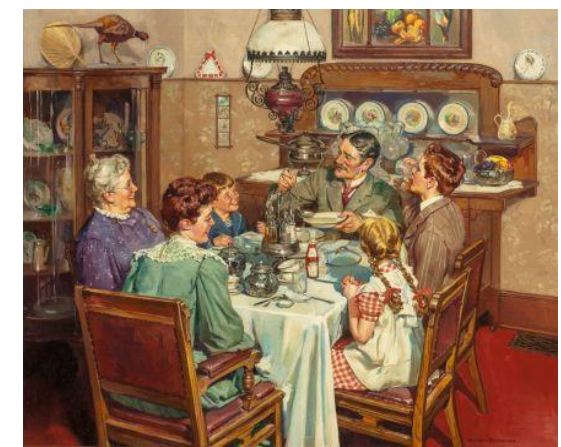

Cuadro 4. H. Anderson. A good table as american 


\section{EL EXPRESIONISMO ABSTRACTO, MUDO TESTIGO DE LA TRAMA EN STERLING \& COOPER}

En este apartado abordaremos el sentido de las obras pictóricas que aparecen en la serie, con énfasis en las de las oficinas de Sterling \& Cooper, espacio en el que transcurre la mayor parte de la acción y el que evoluciona con los eventos históricos y culturales a lo largo de los años.

La bonanza experimentada por EU después de la II Guerra Mundial, su fortalecimiento económico y la migración de artistas e intelectuales europeos convirtieron a ese país y especialmente a la ciudad de Nueva York en el centro rector de las modas culturales de la segunda mitad del siglo XX.

La oficinas de Sterling \& Cooper son el más claro ejemplo de este contexto. La serie da inicio en 1959, cuando el expresionismo abstracto se había colocado como la escuela pictórica dominante, lo cual queda explícito en las paredes de la agencia.

El expresionismo abstracto tuvo sus orígenes en el Federal Art Project, un programa creado desde los años de la Gran Depresión para ayudar a los artistas a quienes se pagaba semanalmente por hace obra en edificios públicos (VV. AA., 2017). Después se trasladó a galerías y centros de arte y para mediados de la década del 50 el arte americano había logrado su propia identidad al desvincularse de la influencia del arte europeo.

No es gratuito el apoyo a una corriente artística que dio obras de gran formato que ocupaban espacios importantes no solo en edificios públicos sino en oficinas, hoteles o centros financieros: el expresionismo abstracto, prescindía de la representación y con ello de cualquier temática relacionada directamente con la actividad humana. Después de una guerra fuertemente ideologizada, una propuesta plástica que abolía cualquier compromiso con problemáticas sociales y que no hacía sino dar fuerza expresiva al color y la forma libres fue realmente bienvenida.

Aparentemente ornamentales e ideológicamente inofensivos, los cuadros de la agencia le dan un halo de esa modernidad.

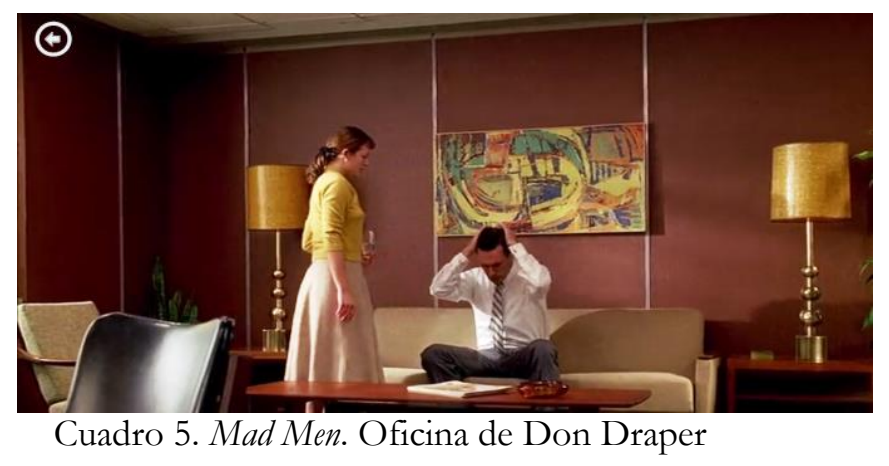

En la oficina de Don Draper vemos un cuadro de Michal Shapiro (cuadro 5) que a 
pesar de ser una artista contemporánea, sus trazos gruesos y el uso de colores directos están en perfecta concordancia con los cuadros abstractos de la época.

Mención especial merece la llegada de un Rothko a la oficina de Bertrand Cooper, hecho que ocupa buena parte de la trama del episodio siete en la segunda temporada.

Si bien los personajes viven rodeados de cuadros del mismo estilo, el de Rothko trae el "aura" del artista, enfatizada por los $10 \mathrm{mil}$ dólares que Cooper pagó por él. Como quien entra a un santuario, un grupo de personajes entra a ver el cuadro descrito por la propia secretaria como "cuadros borrosos" y que detona comentarios como la aguda aseveración de Crane al afirmar que "...tienes dos posibilidades: finges que te gusta, como $\mathrm{El}$ traje nuevo del emperador, o creerá que eres un tonto porque te gusta" (T2E7, palabras de Crane).

En la oficina de Cooper la obra mejor mostrada por la cámara es El sueño de la esposa del pescador, de Katsushika Hokusai, y que representa un enorme pulpo en situación de cópula con una mujer. Un cuadro que en la última temporada va a dar a manos de Peggy, la protagonista que encarna la principal premisa de la serie al respecto de la liberación femenina, quien entra con el cuadro bajo el brazo, lentes oscuros y cigarro en la boca a las nuevas oficinas de McCann en donde verán su final los personajes de Sterling \& Cooper.

En el lento avance de la trama, y de los años, las oficinas presentan algunos cambios que van de la mano con la recomposición de la agencia inicial Sterling \& Cooper. Como signo de los tiempos que se avecinaban, las empresas son absorbidas por otras más grandes, en el imparable ritmo capitalista. Aun así, la pintura prevaleciente sigue siendo abstracta, quizás acercándose en ocasiones al minimalismo y dando lugar, como veremos más adelante, al cartel pop y psicodélico propio de los últimos años 60 , pero no hay cambios contundentes. A fin de cuentas, con todo y los acontecimientos vividos, los personajes también se niegan a cambiar. Sus relaciones personales podrían ser material para grandes melodramas, sin embargo, se mantienen en una suerte de bajo continuo dramático, aferrados a su individualidad, misma que se lleva Draper a su nuevo y moderno departamento una vez que se ha casado con Megan, su joven secretaria. En ese departamento, ocupará un lugar importante un cuadro de Kimm Swank, muy diferente a los de la casa Draper de las primeras temporadas. Es interesante el hecho de que en las casas los cuadros son paisajes, flores, pájaros, y otros motivos tradicionales $y$ 
conservadores. Tienen una personalidad suficientemente anodina como para cubrir su función ornamental sin provocar grandes reacciones. Las obras pictóricas tienen el mismo status que un florero o el papel tapiz de las paredes, están allí por prescripción del gusto socialmente correcto.

La casa de Joan merece también una mirada. Joan es una mujer soltera, en sus treinta, experta en tratar a los hombres y que en la agencia desempeña un papel de secretaria de lujo y asesora. Su sexi forma de vestir y de caminar sale de la caracterización media del resto de las secretarias, para quienes es un ejemplo.

Su casa tiene un forzado gusto refinado; en ella abundan los motivos japoneses que al parecer eran la moda en las casas acomodadas, junto a las lámparas Tiffani o los sofás Dunbar que por cierto, aparecen en la casa de Don Draper. A Joan no la vemos mucho en su papel doméstico pues su protagonismo en la empresa es irremplazable, aun así, hay algunos indicios de su posición sobre lo que significa ser ama de casa ("no dirán que tu mujer no sabe poner una mesa" le diría Joan a su fugaz marido al preparar una cena para su jefe).

A pesar de ser portadora del pensamiento más liberal sobre el rol femenino en Sterling \& Cooper (esto queda claro al inicio de la se- rie cuando lleva a Peggy al ginecólogo para que le recete sus primeros anticonceptivos), la casa de Joan también es un contra discurso visual, con sus paredes color pastel y sus cuadros tradicionales, lo que sugiere el armado de un personaje redondo y complejo, más allá que su aparente estereotipo de femme fatale.

Por otro lado, Pete Campbell es en la agencia la voz de la juventud ocupando su lugar en el mundo de los negocios. Campbell y sus contemporáneos no usan sombrero (Drapper y Sterling lo hacen), tampoco tiene mucho prejuicio para trabajar con judíos o japoneses (Sterling no olvida el trauma de la II Guerra Mundial). Es un hombre ambicioso. Al contraer nupcias con Trudy, la hija de un empresario rico, la joven pareja pone un departamento digno de las revistas de diseño de la época. Sobresalen algunos cuadros y adornos al estilo Witco o Tiki, arte de reminiscencias primitivas muy de moda en la estética de mediados del siglo.

Volviendo al espacio de la agencia, un caso único es Roger Sterling, uno de sus fundadores, que en sus cincuentas se comporta como un gigoló. En la cuarta temporada estrenará un audaz espacio modernista con cuadros de Lisa Gizara, diseños de Eero Saarinen y una pared completa con un tapiz tipo Bridget Riley (no es gratuito que este personaje, con 
todo y el pelo blanco y su pertenencia a la generación posguerra es el primero en consumir LSD y ver con buenos ojos a la psicodelia).

\section{LA IRRUPCIÓN DE LA CONTRA- CULTURA}

"Mad Men, aunque de un modo lateral, se ocupaba del nacimiento de la contracultura, de la extraña, cruda, radical oposición al sistema en la que me formé a lo largo de los años sesenta" (Vila Matas, 2016, p. 59).

$\mathrm{Al}$ inicio de este trabajo se menciona la exposición This is Tomorrow, del grupo Independiente, que marcó el inicio del arte pop, término utilizado por el crítico británico Lawrence Alloway para definir imágenes populares y temas tomados de la comunicación de masas (Masota y Longoni, 2004). Después de su rápida expansión en Estados Unidos el pop se convirtió en un estilo de vida, en la manifestación plástica de una cultura dominada por los medios y la moda. La producción en serie, que tanto contribuyó a la fama de Warhol, terminó con el concepto de lo único (Benjamín, 1989), permitiendo la aceptación del arte que genera productos para un gusto homogeneizado, masificado.

Paradójicamente, en la serie no aparecen obras del arte pop del mismo modo que los cuadros clásicos o abstractos, no deja de llamar la atención que nunca se haga alusión a Warhol, a Lichtenstein, a George Segal; sin embargo, las manifestaciones pop permean la serie, junto con la contracultura: la protesta juvenil, los movimientos pacifistas, las drogas, la psicodelia y el hippismo.

En el capítulo Babylon, de la primera temporada se anuncian ya los visos de la nueva sociedad: Peggy logra un trabajo como copy en la agencia con lo que inicia su ascenso profesional en un mundo dominado por el poder masculino y Don acompaña a Midge y unos amigos a una presentación de poesía y música alternativos, que culmina precisamente con la interpretación de "Por las aguas de Babilonia".

En la tercera temporada, mientras la generación mayor de la agencia está en la tradicional fiesta tipo Kentucky ofrecida por Sterling que nos remite una vez más a las viñetas ilustradas, los más jóvenes fuman mariguana en la oficina, lo que se irá convirtiendo en una práctica cada vez más frecuente.

En las últimas temporadas, vemos escenas de experimentación con LSD, sesiones con Timothy Leary, comunas hippies (a una de ellas se va la mimada hija de Sterling) y fiestas psicodélicas. Esta nueva etapa trae consigo un embate pictórico y estético que va dejando atrás la elegancia neoyorkina para dar paso al 
color y a la liberación de las formas sociales (McRobbie, 2004). En este contexto, liberado del sombrero Fedora y las asfixiantes atmósferas de los bares neoyorkinos, Draper tiene su último insight: coptar a la contracultura para ponerla al servicio de ícono de consumo del siglo XX: la Coca-Cola.

\section{CONCLUSIONES}

La ficción televisiva actual devela cada vez con más claridad su complicidad con la codificación del cine y el resto de las artes. El discurso que la narratología califica como "polifónico" hace posible una verdadera degustación estética en cada visionado de aquellas series que han puesto énfasis no solo en el abordaje de una narrativa más compleja o de temáticas audaces sino en los aspectos formales. En el caso de Mad Men, su compromiso con la construcción de la imagen va más allá de una articulación correcta de los recursos icónicos. Además de la expresividad del plano y la elocuencia de la fotografía que imprime siempre el carácter deseado a la atmósfera que envuelve a los personajes, el diseño de arte ha sido reconocido en múltiples ocasiones por la acertada selección de colores, objetos, mobiliario y demás elementos que constituyen los indicios principales sobre la época, la moda y las tendencias del momento.
María de Lourdes López Gutiérrez

En el terreno del arte y su presencia en la serie, éste ha sido asimilado en las dos vertientes analizadas: como principio de composición y como presencia en la escena.

En el primer sentido, son frecuentes las analogías de la serie con la estética de Edward Hooper. La singularidad de este hecho radica, sin embargo, en que, en estricto sentido, la pintura y la serie representan mundos opuestos, pero el paralelismo en la composición produce un efecto similar: la soledad del individuo en un universo fuertemente marcado por las pautas del desarrollo y el progreso. Coincido con Wim Wenders quien en una entrevista otorgada al diario El País, afirmaba: “...amo de ese pintor la ausencia de detalles; ese ir a lo mínimo indispensable. Hay sitios de los Estados Unidos donde pones la cámara y te sale un cuadro de Hopper" (El Pais, 19 de agosto, 2005).

La fuerza narrativa de Mad Men gira mucho en torno a la enigmática personalidad de su protagonista, Don Draper, cuyo arco dramático se va trazando de forma pausada, sin caer en el efectismo melodramático que muchas de las situaciones planteadas podrían provocar. Los personajes con los que Draper comparte protagonismo, como Peggy, Joan o Pete Campbell tienen también una fuerza interna y un ímpetu individualista que los hace 
superponer sus intereses de éxito profesional y social a los de la familia. Por ello resulta paradójica la composición de los cuadros familiares tan asociados a la ilustración clásica norteamericana, promotora de un estilo de vida muy lejano al que llevan los protagonistas de la serie.

En cuanto a la presencia del arte, la contundencia con la que el abstracto es parte de la iconografía de Sterling \& Cooper no puede pasar inadvertida: es el espacio de la modernidad, de la audacia y del éxito de la forma sobre el contenido. A fin de cuentas, y aun cuando la pintura abstracta no nace en Estados Unidos, es el expresionismo abstracto el que abre las puertas mundiales al arte estadounidense, colocándolo como paradigma dominante en las tendencias pictóricas de la posguerra; su oposición a los cuadros que se adivinan en las casas es muy clara. La agencia es luminosa, geométrica, amplia y colorida; las casas, sobre todo la de Draper y Sterling, son espacios recargados y asfixiantes; en ellos reposan los objetos que una típica pareja de la clase media acomodada ha ido adquiriendo con los años. El espacio como recurso narrativo es uno de los grandes aciertos de la serie.
Por último, y lo que más llama la atención, es la forma como se presenta la revolución social de los sesenta, en el terreno de la estética, a lo largo de las temporadas. Mad Men es una serie fuertemente focalizada desde los sectores más conservadores y aparentemente puritanos de la sociedad norteamericana; lo que impera en su estilo de vida es la doble moral. Este mundo se vio impactado por las ideas liberales y los profundos cambios sociales como la reivindicación de las minorías, la libertad sexual, el ascenso profesional de las mujeres, las drogas psicodélicas, el new age, el rock, el hippismo y la pérdida de las acartonadas formas sociales de la generación de la posguerra.

El impacto, sin embargo, se da con la misma cadencia que los arcos dramáticos: es lento, va ganando terreno en las paredes que se llenan de carteles con flores, en las minifaldas de las mujeres, en la incipiente rebeldía de los hijos más jóvenes, hasta lograr que todos sucumban al embate contracultural que será legitimado, también a fuego lento, hasta ocupar un lugar preponderante en la configuración cultural de las sociedades occidentales. 


\section{FUENTES CONSULTADAS}

Adams, J. (2012). The epic of America. Estados Unidos:T ransaction publishers.

Aumont, J. (1992). La imagen. Barcelona, España: Paidós Ibérica.

Barthes, R. (1977). "Introducción al análisis estructural de los relatos". En: Silvia Niccolini (comp.). El análisis estructural. Buenos Aires, Argentina: Centro Editor de América Latina.

Benjamin, W. (1989). La obra de arte en la época de su reproductibilidad técnica. Buenos Aires, Argentina: Taurus.

Berger, J. (2005). Modos de ver. México: Ed. Gustavo Gili.

Bernárdez, C. (2012). De Coopley a Wesselman, apuntes para una historia de la pintura de Estados Unidos a través de la colección Thysen Bornemisza. Madrid, España: Museo Thysen Bornemisza.

Casseti, F. y Di Chio, F. (1991). Cómo analizar un film. Barcelona, España: Paidós.

Cuadrado, A. (2011). "El estilo de Mad Men. La desarticulación del drama televisivo". En: Revista Comunicación, núm. 9, vol. 1, 34-48. España: Universidad de Sevilla.

Gaudreault, A. y Francois, J. (1995). El relato cinematográfico. Barcelona, España: Paidós Comunicación.

McRobbie, A. (1994). Postmodernism and popular culture. London, UK: Routledge.

Martin, B. (2013). Dificult men. Behind the scenes of a creative revolution: from The Sopranos and The Wire to Mad Men and Breaking Bad. New York, USA: The penguin Press.

Massota, O. y Longoni, A. (2004). Revolución en el arte: pop-art, happenings y arte de los medios en la década del sesenta. Buenos Aires, Argentina: Edhasa.

Reed, W. (2001). The ilustrator in America, 1860-2000. USA: The Society of Ilustrators.

Ros, E. (2015). "Spleen americano: Don Draper en los infiernos". En: VV. AA. Mad Men o la frágil belleza de los sueños en Madison Square. Madrid, España: Errata Naturae.

Souter, G. (2015). American realism. USA: Parkstone Press International.

Vila-Matas, E. (2015). "Peggy no se casó". En: VV. AA. Mad Men o la frágil belleza de los sueños en Madison Square. Madrid, España: Errata Naturae.

VV. AA. (2017). Expresionismo abstracto. Madrid, España: Turner Ediciones.

Wells, W. (2012). Silent theater. The art of Edwar Hooper. USA: Phaidon. 


\section{ELECTRÓNICAS}

Dunbar. http://www.collectdunbar.com/about-us.

Michal S. http://michalshapiro.com/set-home-office-mad-men/.

National Museum of American Ilustration. http:/ / americanillustration.org/.

Liberty Magazine Historical Archive, 1924-1950. http://www.gale.com/liberty-magazine-1924-1950/.

Parker, M. Why we love midcentury modern design. 15/07/13. Houzz. http://www.houzz.com/ideabooks/14393727/list/why-we-love-midcentury-modern-design.

Reviriego, C. "La soledad hopoperiana de Dick Whitman”. El Cultural, junio, 2013. http://www.elcultural.com/blogs/to-be-continued/2013/06/la-soledad-hopperiana-de-dickwhitman/.

Silver, Leigh, Andrew, Lasan, et. al. Artoholics: breaking down the art you missed in Mad Men. Complex Style. 09/04/2014. http://www.complex.com/style/2014/04/breaking-down-the-art-on-madmen/. 